\title{
Die Theorie der komparativen Kosten (von David Ricardo)
}

avid Ricardo erklärt das Theorem der komparativen Kosten am Beispiel des Kleidungs- und Weinhandels zwischen England und Portugal. Warum er das als Beispiel gewählt hat? 2wischen 1703 und 1842 bestand zwischen England und Portugal ein Abkommen über den zollfreien Austausch von britischem Tuch und portugiesischem Wein.
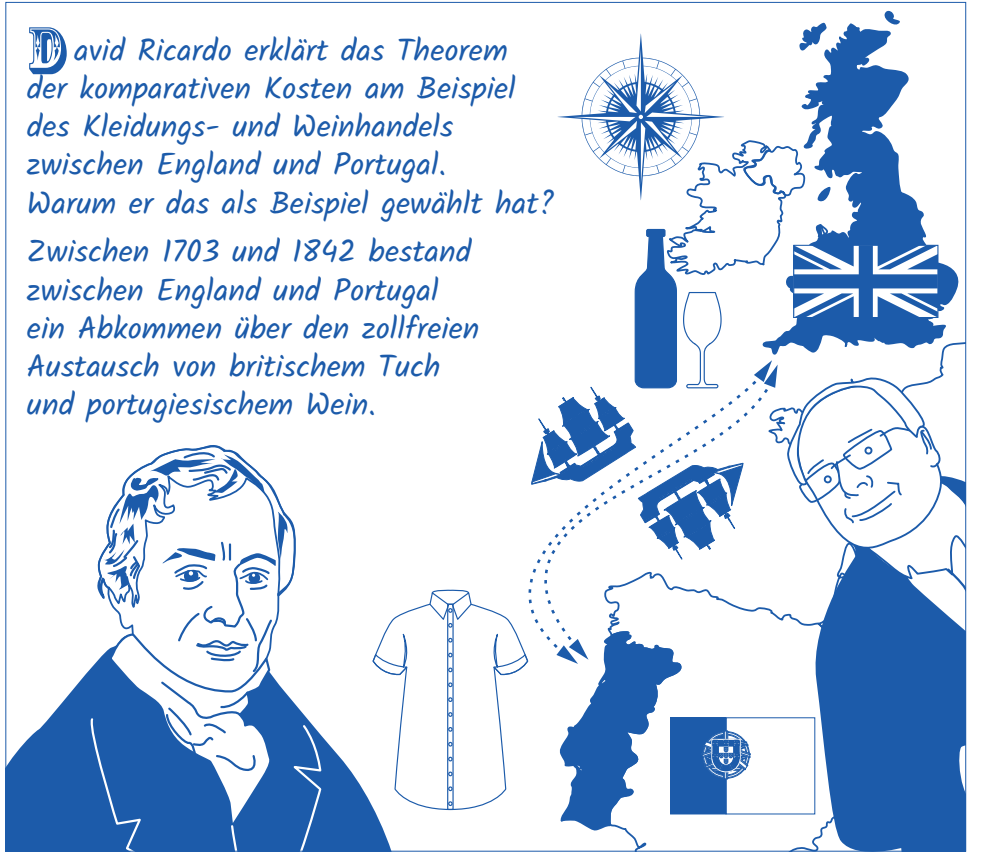

\section{Wein}

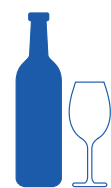

England 120 Arbeitskräfte

Portugal 80 Arbeitskräfte

\section{initiviti}

\section{Kleidung}

England 100 Arbeitskräfte

Portugal 90 Arbeitskräfte

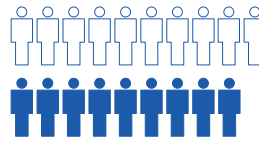

Portugal kann beide Produkte, Kleidung und Wein, mit geringerem Aufwand, also absolut betrachtet, günstiger herstellen. Trotzdem lohnt es sich für Portugal, mit England Handel zu treiben. Denn, relativ gesehen, also komparativ, kann England Kleidung günstiger als Portugal herstellen.
Nehmen wir an, dass England zur Kleiderherstellung 100 Arbeitskräfte pro Jahr und zur Weinherstellung 120 Arbeitskräfte benötigt, braucht Portugal zur Herstellung der gleichen Menge Kleidung und Wein 90, beziehungsweise 80 Arbeitskräfte.
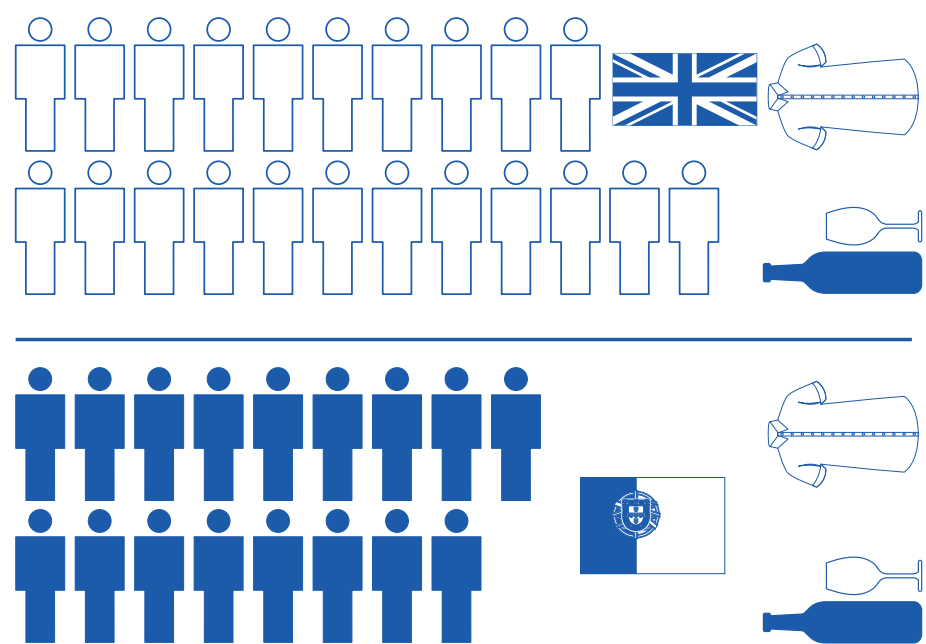

Jedes Land sollte sich auf das konzentrieren, was es am relativ günstigsten herstellen kann. Da man Kleidung aber nicht trinken kann und Wein nicht anziehen, muss Handel getrieben werden.

Ohne Handel:

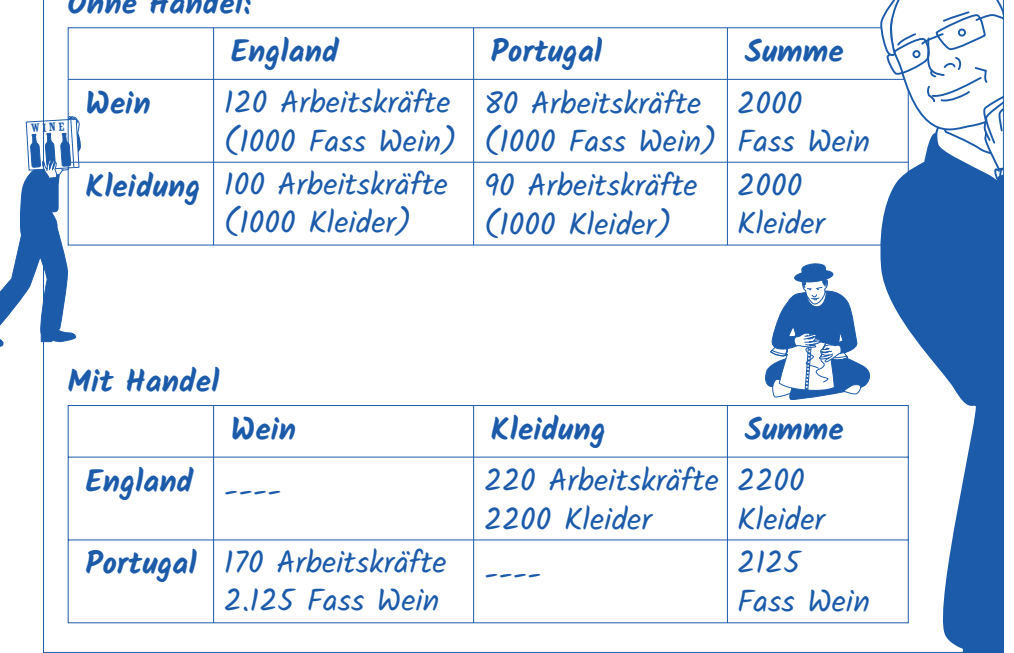

Di Theorem der komparativen Vorteile veranschaulicht, dass sich Handel lohnt, und sich beide Volkswirtschaften, in diesem Fall England und Portugal, auf ein höheres Wohlfahrtsniveau gelangen. Es stehen mehr Kleidungsstücke und mehr Wein zur Verfügung,

als wenn kein Handel getrieben wird. Handel wirkt damit wie eine Erhöhung der Produktivität oder eine Vermehrung der Faktoreinsatzmengen. Allerdings: Ricardo unterstellt in seinem Modell Vollbeschäftigung und dass Arbeitskräfte einer Branche sofort in einer anderen Branche eine Anstellung finden. Ist der Arbeitsmarkt nicht vollkommen flexibel, kann auch das zu Problemen führen. Dennoch zeigt das Modell, dass auch Länder, die in der Produktion aller Produkte einen Nachteil haben (in unserem Beispiel England), gewinnbringend am internationalen Handel teilnehmen können.
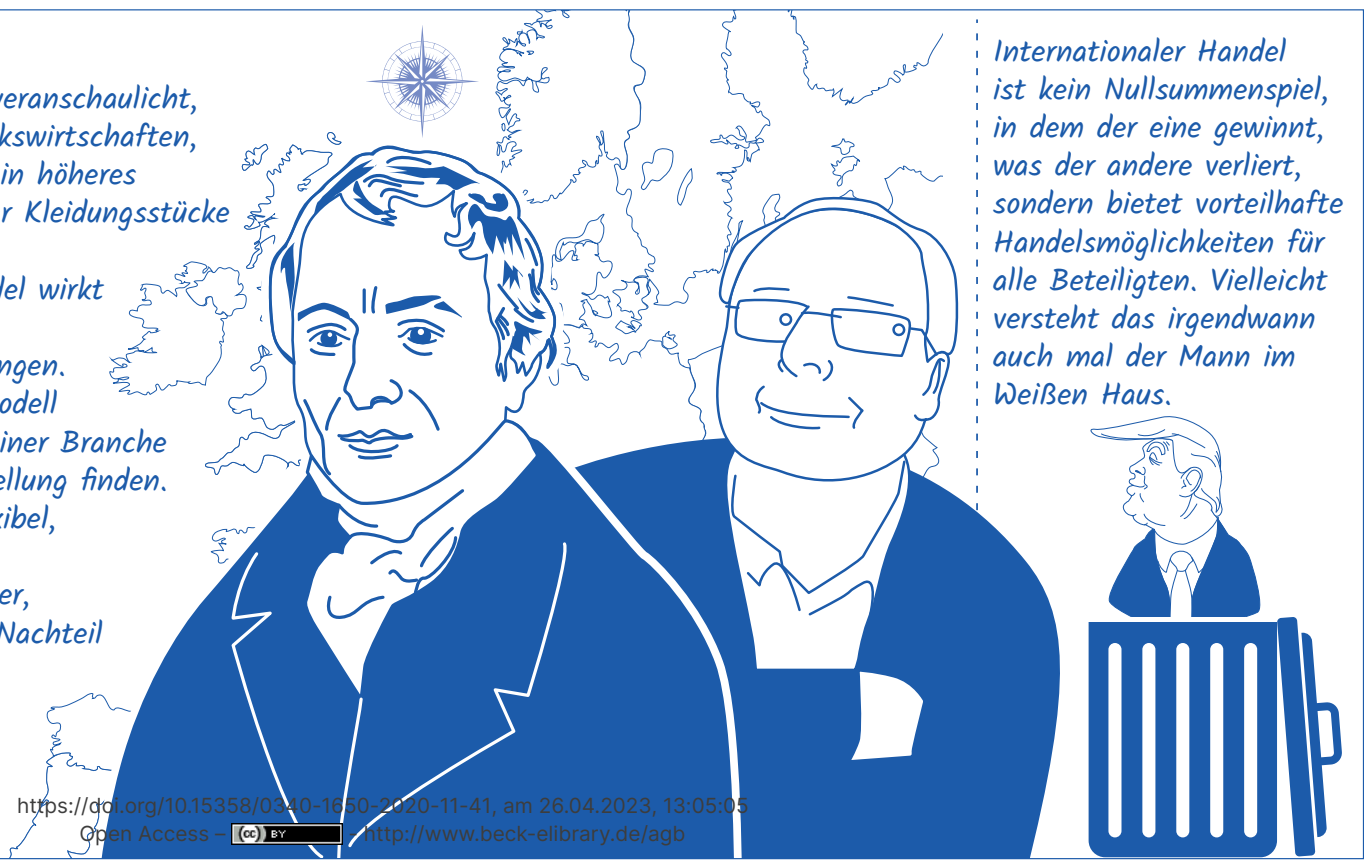